\title{
Development of Self Power Generating Conventional Bicycle
}

\author{
Abhishek Kandalkar ${ }^{[1]}$, Nayan Pawar ${ }^{[2]}$, Uday Patil [3] , Tejas Pakhale ${ }^{[4]}$. Prof. Amit Kharche [5] \\ D Y Patil School of Engineering Academy Ambi, Talegaon Dabhade.
}

\begin{abstract}
Now days, an electric bicycle is attracting more people's attention around the world because it is one of the environmentally friendly vehicles as well as zero emissions from the vehicle. In order to develop a high-performance electric bicycle, various operating characteristics are considered such as riders' mass, wind speed and slope. Main components of this bicycle are Dynamometer, Battery.

The main use of Dynamometer is to absorb the power generated. Regenerative dynamometers, in which the prime mover drives a DC motor as a generator to create load, make excess DC power. When the bicycle starts running then the energy through chain and sprocket given to dynamometer and then to the battery which stores the energy. This stored energy is used to drive the bicycle which reduces the human efforts $\&$ increases the comfort level of human.
\end{abstract}

Keywords: Travelling Electric Bicycle, Electric Energy, Fuel Economy, pollution, noise.

\section{i. INTRODUCTION:}

Recently, the world is facing with big challenges including depletion of fossil fuels and global warming caused by exhaust emissions from conventional vehicles fuelled with gasoline or diesel. In this situation, electric vehicles $(E V s)$ have a great potential to overcome these challenges. As we know fossil fuel produce harmful gasses which are harmful for human being and this gas produce pollution in atmosphere due to which depletion of ozone layer happened, to reduce this we make a electric vehicle.

This vehicle works on charging. In this vehicle dynamometer is provided which generate current and simultaneously charge the battery due to this vehicle running time increases. Vehicle is pedal assist there for when the vehicle get discharge it run on peddle and produce current similarly. Some e-bikes have an electric motor that operates on a power-on-demand basis only. In this case, the electric motor is engaged and operated manually using a throttle, which is usually on the handgrip just like the ones on a motorbike or scooter. These sorts of e-bikes often, but not always, have more powerful motors than pedelecs do.

The EV work on driver demand ride by pedal power alone, i.e. fully human-powered. Ride by electric motor , alone by operating the throttle manually, ride using both together at the same time.

\section{ii. LITERATURE SURVEY:}

1. Paper Name: A simulation and experimental study of

operating performance of an electric bicycle integrated with a semi-automatic transmission.

Author: Nguyen Ba Hung ${ }^{[1]}$, Jaewon Sung ${ }^{[2]}$, Ocktaeck $\operatorname{Lim}^{[3]}$.

Description: The objective of this study is to investigate the dynamic characteristics and optimize the required power of an electric bicycle equipped with a semi-automatic transmission. In this simulation, we analyze the dynamic characteristics and operating characteristics of an electric bicycle at each gear ratio based on the effects of input parameters such as gearspeed, frontal area, and slope grade by using MATLAB-Simulink. Through this simulation, an analysis is conducted to maximize the power generation of the electric bicycle. The simulation results show that the required power can be optimized by changing the key parameters mentioned above. In addition, a model-based control study is conducted to control the bicycle speed under the effects of gearspeed and slope grade. We also Conduct an experiment on a real road and analyze the dynamics and required power of the electric bicycle. The experimental results agree well with the simulation results at each transmission ratio. This combination of simulations and experiments provides a useful method to estimate the power requirements for the motor of an electric bicycle.

\section{Effects of rider's mass on velocity:}
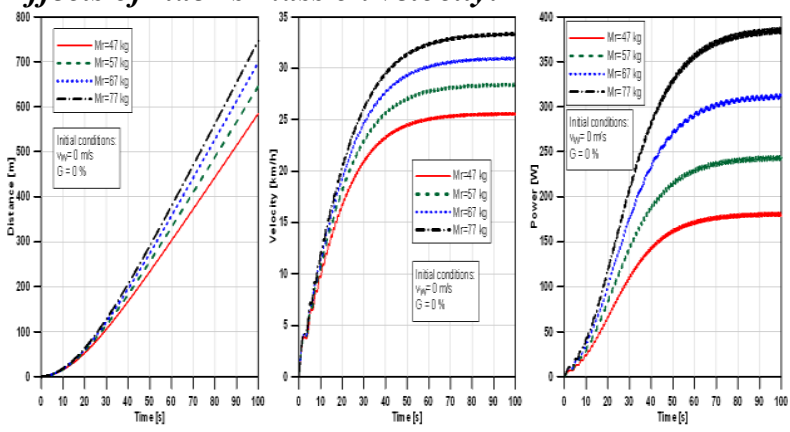

Figs. $a$ and $b$ show that the distance and velocity of the bicycle increase by adjusting rider's mass from $\mathrm{Mr}=47$ $\mathrm{kg}$ to $\mathrm{Mr}=77 \mathrm{~kg}$. This is because the inertial force is increased when increasing rider's mass. The increased velocity of the bicycle results in increasing of required power, as shown in Fig. 3. Therefore, the rider's mass $(\mathrm{Mr}=77 \mathrm{~kg})$ is selected as an input parameter for the next investigation of effects of wind speed. 

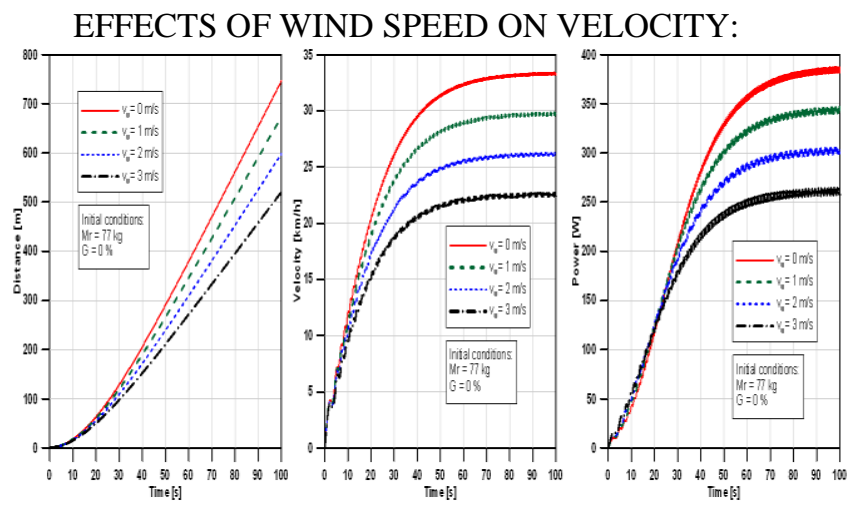

Figs. $a, b$ and $c$ show effects of wind speed on the distance, velocity and required power of the bicycle, respectively.

The simulation Results show that the lower wind speed, the higher distance, velocity and required power. This is explained by reduced wind resistance force when the wind speed reduces. The maximum velocity and required power are found at $\mathrm{vw}=0 \mathrm{~m} / \mathrm{s}$ with values of $33.4 \mathrm{~km} / \mathrm{h}$ and $387.2 \mathrm{~W}$, respectively. Thus, wind speed $\mathrm{vw}=0 \mathrm{~m} / \mathrm{s}$ is selected for the next investigation of effects of slope.

The dynamics and required power of an electric bicycle have been simulated through dynamic equations. Effects of input parameters such as rider's mass, wind speed, and slope on the dynamics and required power of an electric bicycle were investigated. The simulation results showed that the maximum required power of the electric bicycle was obtained around 387.2 Watt, corresponding to Mass $\times$ radius $\mathrm{r}=77 \mathrm{~kg}, \mathrm{vw}=0 \mathrm{~m} / \mathrm{s}$ and $\mathrm{G}=0 \%$.

An experimental study was also conducted to support the presented simulations. This study showed that the simulation results were validated by experimental results. In addition, the simulation and experimental study indicated the way to select a suitable power for motor of the electric bicycle.

We analyze the dynamic characteristics and operating characteristics of an electric bicycle at each gear ratio

2. Paper Name: Design and Fabrication of low Low-

Electric Bicycle .

Author: Boopathi S. ${ }^{[1]}$, Saranya A. ${ }^{[2]}$, Raghuraman S. ${ }^{[3]}$, Revanth R. ${ }^{[4]}$.

Description: Now days the automobile industry become more competitive the vehicles can get the energy from petrol or diesel engine for its drive. The recent years ebike became more attractive and less maintenance cost. However only drawback of e-bike is requiring frequent charging form EB supply. In this project is based charging arrangement on the e-bike. electric energy from battery and battery can receive electric energy from hub dynamo. This energy is stored in battery. Market available e-bike batteries are designed to spent 6-8 hours/charge by using EB supply. This e-bikes running cost is very low, when compare to other sources of energy. Today available e-bike are using 3-4 numbers of $12 \mathrm{v}$ batteries. In this project only use one $24 \mathrm{v}$ battery, the battery cost is reduced. These batteries are charged by Hub dynamo. The electric supply cost also reduced. Mechanical engineering, deals with studies related to Torque control, human power, and pendulums or systems stability. In this area, there is still potential for improvement, particularly in the search for lighter materials. This weight relief would also allow certain types of electric bicycles to be adapted to the regulations of countries whose restrictions are based on the weight of the bicycle.

According to this research we decided to use a bicycle which is light in weight and easy to maintenance. Due to selection of bicycle body the performance of vehicle increased by 28 percent.

3. Paper Name: Electric bicycle management and control

at a signalized intersection.

Author: Hui Ou ${ }^{[1]}$, Tie-Qiao Tang ${ }^{[2]}$, Ying-Xu Rui ${ }^{[3]}$, Jie-Ming Zhou ${ }^{[4]}$

Description: Electric bicycle (EB) has been one popular traffic tool in urban traffic system, but it has some disorder motion behaviors at a signalized intersection. In this paper, we propose a

Strategy to control each EB's motion at a signalized intersection, and design some rules to explore each EB's motion and the impacts of the proposed strategy on each EB's motion at the signalized intersection. The numerical results indicate that the proposed strategy can enhance the operational efficiency at the signalized intersection.

This paper gives idea about the signalized control of electric bicycle and management of control during running of vehicle.

by understanding this paper we provide indicator ,horn , flash lamp speed indicator to the electric bicycle.

\section{iii. Component used:}

\section{- FRAME:}

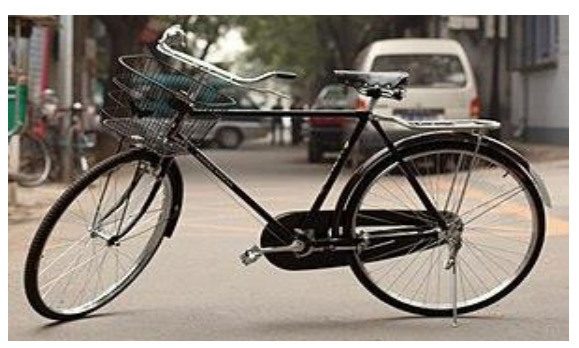

Bicycle, also called a cycle or bike, is a humanpowered or motor-powered, pedal-driven, single-track vehicle, having two wheels attached to a frame, one behind the other. 


\section{- DYNAMOMETER:}

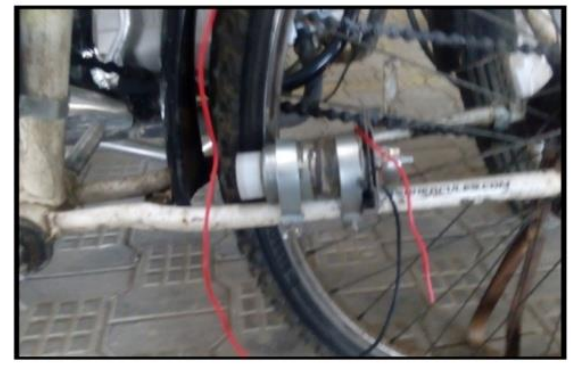

Bicycle dynamo is a source of lighting attached to the cycle to make it easier and more comfortable for the rider when biking on roads, especially during nights.

This dynamo is actually a small generator that produces illumination with the normal action of peddling the bike. It is a good way to make biking safe for the rider without spending any money.

\section{- MOTOR:}

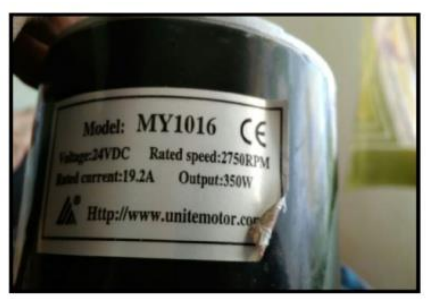

Brushless DC motor is any of a class of rotary electrical machines that converts direct current electrical energy into mechanical energy.

The motor is having 350 watt. Capacity with maximum $2750 \mathrm{rpm}$.

Its specifications are as follows: Current Rating: $19.2 \mathrm{amp}$,

Voltage Rating: 24 Volts , Cooling: Air - cooled.

\section{- .MOTOR CONTROLLER:}

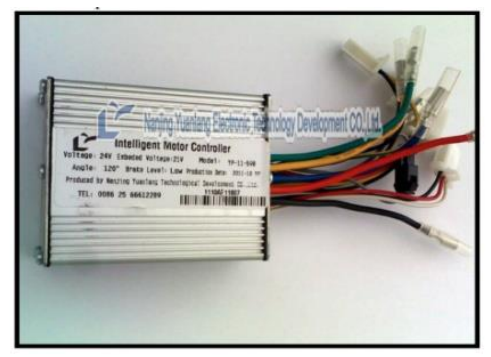

A motor controller is a device or group of devices that serves to govern in some predetermined manner the performance of an electric motor.
- BATTERY:

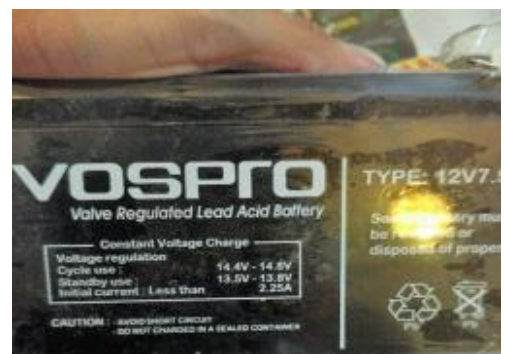

The battery also acts as a condenser in a way that it stores the electric energy produced by the generator due to electrochemical transformation and supply it on demand. Design and Fabrication of Battery is also known as an accumulator of electric charge.

- Chain Drive:

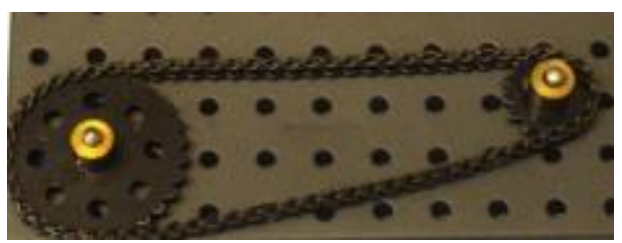

A Chain is an array of links held together with each other with the help of steel pins. This type of arrangement makes a chain more enduring, long lasting and better way of transmitting rotary motion from one gear to another.

The major advantage of chain drive over traditional gear is that, the chain drive can transmit rotary motion with the help of two gears and a chain over a distance whereas in traditional many gears must be arranged in a mesh in order to transmit motion.

- Sprocket:

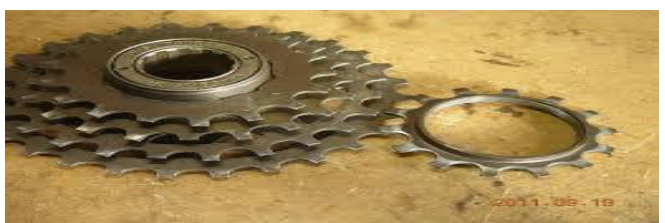

Sprockets have many engaging teeth but gears have only one or two.

The teeth of a gear touch and slip against each other but there is basically no slippage in case of sprocket. The shape of the teeth. 
iv. CALCULATIONS:

\section{Chain Design:}

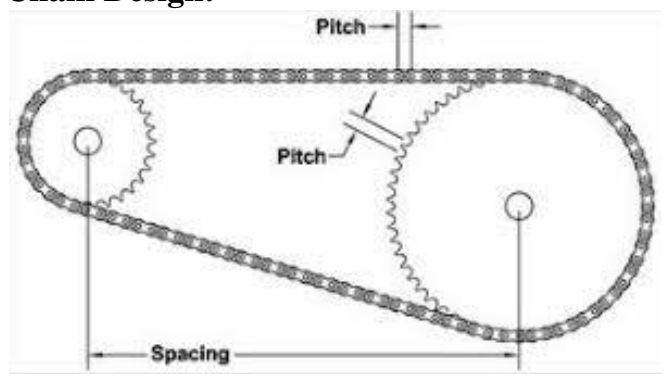

Selecting standard chain used in cycle as Chain - From

Design of Machine Elements by [V.B. Bhandari].

Pitch $-9.525 \mathrm{~mm}$

1. Roller diameter, $\mathrm{d} 1=6.35 \mathrm{~mm}$

Width, $\mathrm{b}_{1}=5.72 \mathrm{~mm}$

2. Transverse pitch $p_{\mathrm{t}}=10.24 \mathrm{~mm}$

$\mathrm{Z}_{1}=18$

$\mathrm{Z}_{2}=44$

3. Approximate centre distance:

$\mathrm{a}=40 \times \mathrm{P}$---------------nominal

$\mathrm{a}=40 \times 9.525$

$\mathrm{a}=381 \mathrm{~mm}$

4. No of links:

$\mathrm{L}_{\mathrm{n}}=2(\mathrm{a} / \mathrm{p})+\left(\mathrm{z}_{1}+\mathrm{z}_{2} / 2\right)+\left(\mathrm{z}_{2}-\mathrm{z}_{1} / 2 \times \pi\right)^{2} \times(\mathrm{p} / \mathrm{a})$

$=2(381 / 9.525)+(18+44 / 2)+(44-18 / 2 \times \pi)^{2} \times$

$(9.525 / 381)$

$=111.43$

$=111$

5. Corrected center distance:

$\mathrm{a}=\mathrm{p} / 4\left\{\left[\mathrm{~L}_{\mathrm{n}^{-}}\left(\mathrm{z}_{1}+\mathrm{z}_{2} / 2\right)\right]+\left(\left[\mathrm{L}_{\mathrm{n}^{-}}\left(\mathrm{z}_{1}+\mathrm{z}_{2} / 2\right)\right]^{2}-8 \times\left(\mathrm{z}_{2^{-}}\right.\right.\right.$ $\left.\left.\mathrm{z}_{1} / 2 \times \pi\right)^{2}\right)^{1 / 2}$

$\mathrm{a}=378.9 \mathrm{~mm}$

$\mathrm{a}=379 \mathrm{~mm}$

6. Length of the chain:

$\mathrm{L}=\mathrm{L}_{\mathrm{n}} \times \mathrm{p}=111 \times 9.525=1057.28 \mathrm{~mm}$

Design of sprocket

For $\mathrm{Z}=18$

Pitch, $\mathrm{P}=9.525 \mathrm{~mm}$

Width between inner plates, $b_{1}=5.72 \mathrm{~mm}$

Roller diameter, $\mathrm{d}_{1}=6.35 \mathrm{~mm}$

Transverse pitch $\mathrm{p}_{\mathrm{t}}=10.24 \mathrm{~mm}$.

1. Pitch circle diameter:

$\mathrm{D}_{1}=\frac{p}{\sin (180 / z 1)}$
$=\frac{9.525}{\sin (180 / 18)}$
$\mathrm{D}_{1}=54.85 \mathrm{~mm}$

$$
\begin{aligned}
& \mathrm{D}_{2}=\frac{p}{\sin (180 / Z 2)} \\
&=\frac{9.525}{\sin (180 / 44)} \\
& \mathrm{D}_{2}=133.59 \mathrm{~mm}
\end{aligned}
$$

2. Roller seating radius $\left(\mathrm{r}_{\mathrm{i}}\right)$ :

$r_{\text {max }}=0.505 \mathrm{~d}_{1}+0.069 \times\left(\mathrm{d}_{1}\right)^{1 / 3}$

$\mathrm{r}_{\mathrm{i} \text { max }}=3.33 \mathrm{~mm}$

$\mathrm{r}_{\text {imin }}=0.505 \mathrm{~d}_{1}=3.2 \mathrm{~mm}$

3. Tooth Flank Radius $\left(\mathrm{r}_{\mathrm{e}}\right)$ :

$r_{\text {e } \max }=0.008\left(\mathrm{z}^{2}+180\right)=16.928 \mathrm{~mm}$

$\mathrm{r}_{\mathrm{e} \min }=0.12 \times \mathrm{d}_{1}(\mathrm{z}+2)=15.24 \mathrm{~mm}$

4. Root Diameter $\left(D_{f}\right)$ :
$\mathrm{D}_{\mathrm{f}}=\mathrm{D}-2 \times \mathrm{r}_{\mathrm{i}}=88.47 \mathrm{~mm}$

5. Tooth height above pitch polygon $\left(h_{\mathrm{a}}\right)$ :

$\mathrm{h}_{\mathrm{a} \max }=0.625 \times \mathrm{p}-0.5 \times \mathrm{d}_{1}+0.8 \times \mathrm{p} / \mathrm{z}=2.9513 \mathrm{~mm}$

$\mathrm{h}_{\mathrm{a} \min }=0.5\left(\mathrm{p}-\mathrm{d}_{1}\right)=1.5875 \mathrm{~mm}$

6. Tooth Width $\left(\mathrm{b}_{\mathrm{f}}\right)$ :

$b_{\mathrm{f}}=0.93 \times b_{1}=5.3196 \mathrm{~mm}$

Let's assume,

Weight of bicycle $=10 \mathrm{Kg}$

Weight of person sitting on bicycle $=70 \mathrm{Kg}$

So, total weight $=80 \mathrm{Kg}$

Wheel size of bicycle $=622 \mathrm{~mm}=0.622 \mathrm{~m}$

i.e. radius $=0.311 \mathrm{~m}$

Length of bicycle $=6 \mathrm{ft}=1828 \mathrm{~mm}=1.828 \mathrm{~m}$

Rolling friction $=0.01$

Coefficient of drag (This value is totally depending on surface roughness) $=0.88$

Here,

We are assuming expected speed of our bicycle $=$ $25 \mathrm{Km} / \mathrm{hr}$.

Width of bicycle $=2 \mathrm{ft}=609 \mathrm{~mm}=0.609 \mathrm{~m}$

$$
\begin{aligned}
\text { Area } & =\text { length of bicycle } \times \text { width } \\
& =1.828 \times 0.609 \\
& =1.1132 \mathrm{~mm}^{2}
\end{aligned}
$$

Now,

Linear distance $=2 \pi \mathrm{r}$

$$
\begin{aligned}
& =2 \times 3.14 \times 0.311 \\
& =1.953 \mathrm{~m} .
\end{aligned}
$$

Speed $=25 \mathrm{Km} / \mathrm{hr}$.

Velocity $=25000 / 3600=6.94 \mathrm{~m} / \mathrm{s}$

Revolution per minute $(\mathrm{rpm})=$ outer distance travelled/linear distance.

$$
\begin{aligned}
& =25000 / 1.953 \times 60 \\
& =213.34 \mathrm{rpm} .
\end{aligned}
$$

Total Power required $=[$ mass $\times$ acceleration due to gravityx velocityx rolling friction] + [air density $x$ coefficient of drag $\times$ area $\times$ velocity $\left.{ }^{3}\right]$ $\left.6.94^{3}\right]$

$=[80 \times 9.8 \times 6.94 \times 0.01]+[0.6465 \times 0.88 \times 1.113 \times$

$$
=54.409+2011.690
$$

$=266.099 \mathrm{~W}$.

So,

Motor Specification: $\mathrm{P}=250 \mathrm{~W} ; \mathrm{N}=300 \mathrm{rpm} ; \mathrm{T}=7.961$ $\mathrm{Nm}$

Here, we are using 250W and 300rpm motor because it is the standard motor available in the market.

\section{Battery Calculation -}

There is $24 \mathrm{~V}$ battery having $15 \mathrm{Ah}$ capacity

Total Watt power $=24 \times 15$

$$
=360 \mathrm{WH}
$$

Discharge Battery

One-watt motor burns $1 \mathrm{WH}$ in 1 hour. That means 250

W motor burns

$360 \mathrm{WH}=1.44 \mathrm{Hr}$.

Hence, if we drive vehicle at a speed of $25 \mathrm{Km} / \mathrm{hr}$., it 
travels $25 \mathrm{Km}$. in 1 hour.

Our battery runs the motor for $1.44 \mathrm{Hr}$., so total distance traveled will be $36 \mathrm{Km}$.

Time required charging a battery-

The generator or reverse DC motor produces $24 \mathrm{~V}$ at 3 Amp

In order to charge a $24 \mathrm{~V}$ at $3 \mathrm{~A} \mathrm{mp}$

Time $=\mathrm{AH} / \mathrm{Amp}$

$=15 \mathrm{AH} / 3 \mathrm{Amp}$

$=5$ hours

It takes 5 hours to fully charge a $24 \mathrm{~V}$ battery.

Considering the essential factors, it would be ideal to choose lead acid battery over other batteries. It is essential for lead acid battery to charge slowly to prevent heat generation.

\section{v. ADVANTAGES:}

- Easy to commute with low fatigue.

- Less maintenance cost.

- Normal Drag/Pedal is possible when power is not in use.

- Deployable batteries - can be taken inside house.

- Cost of the unit is very low.

- Easy to carry since it is portable.

- Less energy consumed.

- High efficiency can be obtained if inverter is used.

- If using solar panel, free utilization of energy can be done.

\section{vi. DISADVANTAGES:}

- High intensity of wind load.

- High centre of gravity.

- Cannot tolerate drastic changes in environment.

- Needs Periodic Monitoring.

\section{vii. CONCLUSION:}

It can be seen that all vehicle companies are changing to electric engines from existing IC engines. But the problem of electric motors lies in the field of charging the batteries. Our project may provide a solution of this existing problem since charging of battery is done as the vehicle runs. It is very much suitable for young, aged people and caters the need of economically poor class of society. The most important feature of this bicycle is that it does not consume valuable fossil fuels therefore saving the money. It is eco-friendly and pollution free, as it does not have any emission. Moreover, it is noiseless and can be recharged with the AC adapter in case of emergency and cloudy weather.

\section{viii. BIBLIOGRAPHY:}

[1] A simulation and experimental study of operating performance of an electric bicycle integrated with a semi-automatic transmission, BY Nguyen Ba Hung ${ }^{[1]}$, Jaewon Sung ${ }^{[2]}$, Ocktaeck Lim ${ }^{[3]}$

[2] Design and Fabrication of low Low-Cost Electric Bicycle. by boopathi $\mathrm{s}^{[1]}$,saranya a ${ }^{[2]}$, raghuraman $\mathrm{s} .{ }^{[3]}$, revanth $\mathrm{r} .{ }^{[4]}$.

[3] Electric bicycle management and control at a signalized intersection by Hui Oua ${ }^{[1]}$, Tie-Qiao Tangb ${ }^{[2]}$, Ying-Xu Ruib ${ }^{[3]}$, Jie-Ming Zhoua ${ }^{[4]}$ 